\title{
A PRODUÇÃO ACADÊMICA SOBRE USO PÚBLICO EM UNIDADES DE CONSERVAÇÃO NAS REVISTAS ELETRÔNICAS DE GEOGRAFIA FLUMINENSE DE 2010 A 2020
}

\section{FLÁVIO LAPLACE DE ANDRADE ${ }^{1}$}

\section{DOI}

https://doi.org/10.47977/2318-2148.2020.v8n12p39

\begin{abstract}
RESUMO
O objetivo deste trabalho é fazer um levantamento quantitativo sobre a produção acadêmica envolvendo o tema 'uso público em unidades de conservação'. A gestão, a visitação e a prestação de serviços nas unidades de conservação (UC) foram importantes referências para o tema, pois estes estudos são relevantes como fator de proteção dessas áreas em relação aos impactos ambientais e sua preservação, em geral. Foram eleitas quatro revistas eletrônicas do Estado do Rio de Janeiro no período de 2010 a 2020 (11 anos), considerando suas relevâncias editoriais em cursos de graduação e pós graduação de Geografia. Foi realizado um levantamento da produção de artigos nos periódicos supracitados e elaboração de gráficos com o intuito de evidenciar os possíveis padrões na produção fluminense a respeito do tema. Como objetivo secundário, foram pesquisadas as produções onde as UC foram objetos principais ou como referência de uma área de estudo. Após analisar os dados obtidos, observou-se uma baixa taxa de publicações ao longo do recorte temporal escolhido, inferior a $4 \%$ do total. Todas as revistas tiveram publicações sobre UC, mas somente duas apresentaram artigos mais específicos sobre 'uso público'.
\end{abstract}

Palavras-Chave: Conservação da natureza, áreas protegidas, produção acadêmica

\begin{abstract}
The objective of this work is to make a quantitative survey on academic production involving the theme 'public use in protected areas'. Management, visitation and the provision of services in protected areas were important references for the theme, as these studies are relevant as a protection factor for these areas in relation to environmental impacts and their preservation, in general. Four electronic magazines from the State of Rio de Janeiro were elected from 2010 to 2020 (11 years), considering their editorial relevance in undergraduate and graduate courses in Geography. A survey of the production of articles in the aforementioned periodicals and the elaboration of graphics was carried out in order to highlight the possible patterns in Rio de Janeiro production regarding the theme. As a secondary objective, research was carried out on productions where UCs were the main objects or as a reference in a study area. After analyzing the data obtained, a low rate of publications was observed throughout the chosen time frame, less than $4 \%$ of the total. All magazines had publications on protected areas, but only two presented more specific articles on 'public use'.
\end{abstract}

Keywords: Nature conservation, protected areas, academic production

\section{INTRODUÇÃO}

Atualmente os estudos relativos às unidades de conservação (UC) são de grande importância para preservação dos recursos naturais, assim como para ampliar o conhecimento sobre suas situações territoriais no país. Dentre os tópicos que perpassam o tema, optou-se pelo estudo do uso público, seus atores e impactos. O uso público pode ser definido como o conjunto de atividades que visam o entretenimento dos frequentadores e visitantes nas UC incluindo as atividades educativas, de pesquisa e desenvolvimento pessoal. Depende, fundamentalmente, de ações de planejamento, de gestão e de prestação de serviços essenciais. Essa apropriação se realiza com o intuito de usufruir dos benefícios que áreas naturais protegidas trazem para o ser humano e que serão posteriormente

\footnotetext{
${ }^{1}$ Licenciatura e Mestrado em Geografia pela Universidade Federal Fluminense (UFF/RJ). Professor de Geografia da Rede Municipal de Ensino de Araruama/RJ. E-mail: flaviolaplace@gmail.com
} 
definidas nesse trabalho. Entender as UC na atualidade é perceber que, por mais que busquemos uma preocupação ambiental, continuamos excluindo o homem da natureza como se ele não fosse parte integrante dela.

A ciência geográfica, entre tantos aspectos, pode promover a análise dessas áreas através de trabalhos e pesquisas interagindo com diferentes conceitos geográficos, tais como território, planejamento territorial, espaços turísticos, entre outros. Na atualidade, os trabalhos relativos à origem, gestão e manejo em UC despontam em diversas frentes científicas com a participação de biólogos, sociólogos, ecólogos, entre outros. Os geógrafos também podem examinar de perto a questão, devido a própria necessidade de preservação da natureza em tempos de significativas mudanças tecnológicas e culturais.

Este trabalho teve como objetivo maior levantar quantitativamente a produção acadêmica envolvendo o tema 'uso público em unidades de conservação' em publicações de quatro revistas eletrônicas de Geografia do Estado do Rio de Janeiro (2010 a 2020), vinculadas a cursos de graduação e pós graduação de universidades públicas (federais e estadual). A partir da seleção das revistas, foram estabelecidos padrões de busca dos artigos para produção dos resultados. A importância dos estudos sobre UC, assim como sua relevância para a sociedade, motivou a avaliação em curso, ou seja, gerar uma visão amostral de como o tema das áreas protegidas tem participado na produção do conhecimento geográfico.

\section{UNIDADES DE CONSERVAÇÃO E GEOGRAFIA}

As UC são áreas naturais protegidas, tendo na Geografia um arcabouço teóricometodológico capaz de exemplificar formas e processos que a caracterizam como uma paisagem natural conservada. Pode-se definir unidades de conservação da seguinte forma:

São espaços territoriais e seus componentes, abrangem as águas jurisdicionais, com características naturais relevantes, legalmente instituídas pelo poder público, com objetivos de preservação / conservação e limites definidos, sob regime especial de administração, ao qual se aplicam garantias adequadas de proteção (MINISTÉRIO DO MEIO AMBIENTE, 2020).

São reguladas a partir da Lei 9.985 de 18 de julho de 2000, que instituiu o Sistema Nacional de Unidades de Conservação (SNUC), criado com o objetivo de proteção, elaboração de diretrizes de gestão e planejamento das UC, além de outros fatores de importância para a consolidação da proteção integral.

O tema UC permeia diferentes formas de pensamento. Segundo Diegues (1996) duas correntes traduzem o pensamento sobre espaços naturais e sua interação com o homem, a partir da relação sociedade e natureza. A primeira conhecida como naturalismo reproduz em seu bojo conceitual, um romantismo passado, o mito do paraíso perdido, agora possível de ser reconquistado. Para o naturalismo da proteção da natureza do século passado, a única forma de proteger a natureza era afastá-la do homem, por meio de ilhas onde este pudesse admirá-la e reverenciá-la. (DIEGUES, 1996)

Em outra corrente, conhecida como culturalismo, há debates e reflexões envolvendo as populações tradicionais, a diversidade cultural e o trabalho de demarcação dessas unidades, tendo em vista a questão do pertencimento a terra e seus reflexos na cultura dessas comunidades. Desde tempos remotos o homem busca na natureza o sustento da vida. Para isso, houve a necessidade de demarcar sítios que contivessem os elementos necessários para subsistência como animais, água pura, plantas medicinais, primando pela sua manutenção (MILLER, 1997).

Na modernidade, no entanto, surgem preocupações ambientais com a preservação da flora e da fauna, tendo sido o Parque Nacional de Yellowstone (Estados Unidos, 1872), o primeiro parque natural do mundo resultante da ação governamental de reservar áreas para 
recreação de populações urbanas. Assim, o modelo americano foi exportado para o mundo influenciando diversos países (VALLEJO, 2009).

No Brasil, desde o século XIX, pioneiros, como o engenheiro André Rebouças, posicionaram-se pela criação de Parques Nacionais no Brasil, influenciados pelo modelo de criação de Yellowstone (RYLANDS e BRANDON, 2005). Como afirma Diegues (1996), a ideia de parques ainda consubstanciada pelo pensamento naturalista, foi transposta diretamente dos Estados Unidos para muitos países do "Terceiro Mundo", muitos com uma realidade totalmente dispare da situação americana.

No Brasil, não foi diferente. O estabelecimento das primeiras unidades de conservação, os parques nacionais, obedeceu a critérios estéticos e, só mais tarde, inclusive com a criação de novas modalidades de áreas protegidas, critérios supostamente mais técnicos foram adotados. (BENSUSAN, 2006, p.43)

Em 1934 surgiu o marco legal inicial para a criação de parques nacionais no Brasil com o Decreto 23.793 (Código Florestal), permitido assim a criação do primeiro parque nacional brasileiro, o Parque Nacional do Itatiaia.

Em 1982, durante o III Congresso Mundial de Parques Nacionais, foram destacadas outras proposições e funções, tais como: pesquisa científica, proteção da vida selvagem, preservação de espécies e da diversidade genética, manutenção dos serviços de meio ambiente, proteção de aspectos naturais e culturais específicos, recreação e turismo, educação, uso sustentável de recursos de ecossistemas naturais e manutenção de atributos culturais tradicionais. Estas proposições foram fundamentais para consolidação de uma visão mais moderna e integradora sobre a importância das áreas naturais protegidas nos diversos cenários geográficos do planeta.

\section{USO PÚBLICO EM UNIDADES DE CONSERVAÇÃO}

Ao se propor um levantamento da produção acadêmica, buscou-se analisar conceitos que suscitem o debate e a reflexão. Dentre os temas a serem estudados, o uso público tornase de grande relevância, devido a sua atualidade e as benesses do seu impacto para a natureza e áreas protegidas. Vallejo (2013) utiliza-se da definição do Ministério do Meio Ambiente (2005) ao mostrar que o uso público está inserido no cotidiano das UC, isto é, $o$ processo de visitação, onde se manifestam atividades educativas, de lazer, esportivas, recreativas, científicas e de interpretação ambiental [...] (MINISTÉRIO DO MEIO AMBIENTE, 2005).

O trabalho de Handee et al (1990, apud VALLEJO, 2013) destaca as diversas categorias (Quadro 1) e atores que atuam, direta e indiretamente, no uso público das áreas protegidas. Os gestores atuam no planejamento e manutenção das ações estabelecidas em planos de manejo vinculados aos objetivos de proteção das áreas. São profissionais administrativos, de apoio e gestão que planejam e organizam o uso dos atrativos, definem as possibilidades e restrições de uso, fiscalização, monitoramento, orientação e segurança dos visitantes, gestão financeira e parcerias.

Os visitantes são os 'consumidores' dos atrativos existentes nas UC, incluindo as turistas, esportistas, estudantes, cientistas, religiosos, etc. que irão usufruir do contato direto com a natureza.

Os prestadores de serviços participam das diversas atividades de exploração e atendimento comercial em várias modalidades, tais como: agências de viagens, guias, meios de hospedagem, transporte, alimentação, etc. A prestação de serviços pode acontecer através de iniciativas empresariais, pessoais e/ou via organização comunitária. Destaca-se, neste item, a importância da participação voluntária de grupos e indivíduos que vêm prestando serviços às áreas protegidas. São as organizações não governamentais (ONGs), organizações da sociedade civil de interesse público (OSCIPs) e movimentos voluntários independentes (VALLEJO, 2013). 
QUADRO I - Categorias de uso público na obra de Hendee et. al. (1990)

\begin{tabular}{|l|l|}
\hline \multicolumn{1}{|c|}{ Uso Público } & \multicolumn{1}{|c|}{ Descrição } \\
\hline Recreativo & $\begin{array}{l}\text { Quando os visitantes praticam a recreação (esportes, diversão e } \\
\text { cultura) durante o tempo livre (lazer). }\end{array}$ \\
\hline Comercial & $\begin{array}{l}\text { Exploração realizada através de empresas e guias de turismo e } \\
\text { ecoturismo, meios de hospedagem, alimentação e venda de produtos. }\end{array}$ \\
\hline Científico & $\begin{array}{l}\text { Pesquisadores em trabalhos de investigação científica em diversos } \\
\text { campos do conhecimento (ciências da natureza, geociências, ciências } \\
\text { sociais). }\end{array}$ \\
\hline Educacional & $\begin{array}{l}\text { Programas e atividades de educação e interpretação ambiental, viagens } \\
\text { acadêmicas, treinamentos (sobrevivência, montanhismo, etc) }\end{array}$ \\
\hline $\begin{array}{l}\text { Desenvolvimento } \\
\text { Pessoal }\end{array}$ & $\begin{array}{l}\text { Programas que utilizam a natureza e a aventura no desenvolvimento de } \\
\text { valores de autoconfiança, trabalho em grupo, comunicação e liderança. } \\
\text { Incluem-se nesta classe as atividades de desenvolvimento espiritual e } \\
\text { religioso. }\end{array}$ \\
\hline
\end{tabular}

Fonte: Organizado por Vallejo (2013)

Essas categorias demonstram que as UC geram benefícios para a sociedade e os diversos usos permitem aos visitantes oportunidades de práticas esportivas, estudos acadêmicos e fins educacionais, formais e não formais. Os atores relacionados apontam para a necessidade cada vez maior de estudos que visem abordar o uso público em UC de forma a compreender as particularidades inerentes a esse tema.

\section{OBJETIVO E METODOLOGIA}

O objetivo central do trabalho é levantar a produção de artigos sobre o tema "uso público em unidades de conservação", publicados por um conjunto de revistas eletrônicas de Geografia no período de 11 anos (2010 - 2020). Uma das questões a serem respondidas nesta investigação aborda a dinâmica de publicações de artigos ao longo do período selecionado. Para isso, utilizou-se análise quantitativa simples com a produção de gráficos demonstrativos dos resultados. Comparou-se a produção de artigos sobre 'uso público' com aqueles que fazem referência apenas aos estudos das áreas protegidas, sendo elas UC ou não ${ }^{2}$. Complementarmente, foi produzido um apêndice com os artigos levantados durante a pesquisa.

Para os objetivos do trabalho foram selecionadas quatro revistas (Quadro 2), sendo três delas vinculadas aos programas de Pós Graduação em Geografia de universidades federais (Espaço Aberto - UFRJ, GEOgraphia - UFF e CONTINENTES - UFRRJ) e outra ao Departamento de Geografia da UERJ (Geo UERJ). Dessa maneira, foram contempladas as quatro grandes instituições de ensino da Geografia no estado, sendo três delas federais (UFRJ, UFF e UFRRJ) e uma estadual (UERJ). A revista Espaço Aberto da UFRJ (https://revistas.ufrj.br/index.php/EspacoAberto/index) está disponível virtualmente desde o ano de 2011; a Revista GEOgraphia da UFF (https://periodicos.uff.br/geographia) desde 1999; a Revista Geo UERJ (https://www.e-publicacoes.uerj.br/index.php/geouerj), desde o ano de 1997; e a Revista CONTINENTES da UFRRJ (http://www.revistacontinentes.com.br/index.php/continentes), desde 2012. Todas têm periodicidade semestral.

Cabe ressaltar que algumas universidades e programas de pós-graduação do estado do Rio de Janeiro possuem outras revistas, mas as que foram selecionadas apresentam maior produção e importância científica na área de Geografia.

\footnotetext{
${ }^{2}$ O termo Unidade de Conservação (UC) é utilizado exclusivamente no Brasil, enquanto em outros países adota-se a expressão áreas protegidas de forma genérica. Todavia, no Brasil, a totalidade das áreas protegidas abrange as UC e as APPs (Áreas de Preservação Permanente). As UC, segundo a Lei do SNUC, são os parques, reservas, monumentos naturais, áreas de proteção ambiental, entre outras (12 no total). As APPs abrangem topos de morros, vertentes íngremes, margens de rios, vegetação das zonas costeiras, etc, independentemente de instrumento legal de criação como no caso das UC. (Nota do autor)
} 
QUADRO 2 - Revistas selecionadas para a análise quantitativa.

\begin{tabular}{|c|l|c|c|}
\hline REVISTA & \multicolumn{1}{|c|}{ VÍNCULO INSTITUCIONAL } & $\begin{array}{c}\text { EDIÇÕES } \\
\text { ELETRÔNICAS } \\
\text { DISPONÍVEIS }\end{array}$ & $\begin{array}{c}\text { QUALIS } \\
\text { CAPES }\end{array}$ \\
\hline $\begin{array}{c}\text { ESPAÇO } \\
\text { ABERTO }\end{array}$ & $\begin{array}{l}\text { Programa de Pós-graduação em } \\
\text { Geografia UFRJ. 10 Volumes, 22 } \\
\text { números }\end{array}$ & B3 \\
\hline GEOgraphia & $\begin{array}{l}\text { Programa de Pós-graduação em } \\
\text { Geografia UFF. 22 Volumes, 49 } \\
\text { números. }\end{array}$ & $1999>$ & A2 \\
\hline GEO-UERJ & $\begin{array}{l}\text { Departamento de Geografia da } \\
\text { UERJ. 21 Volumes, 37 números. }\end{array}$ & $1997>$ & B1 \\
\hline CONTINENTES & $\begin{array}{l}\text { Departamento de Geografia da } \\
\text { UFRRJ. 17 números. }\end{array}$ & B3 \\
\hline
\end{tabular}

Fonte: Elaborado pelo autor.

O critério de busca seguiu as seguintes diretrizes:

1. Busca bibliográfica por artigos cujo tema central é 'uso público' em UC, a partir dos aspectos voltados para a gestão, visitação e prestação de serviços em UC. Para isso, selecionamos como tópicos para análise, em cada volume:
A) Título
B) Resumo
C) Palavras-Chave

2. Busca bibliográfica por artigos cujo tema ou objeto de estudo é 'UC'. Para isso, selecionamos como tópicos para análise, em cada volume:
A) Título
B) Resumo
C) Palavras-Chave

3. Quantificação e análise com apoio de gráficos gerados a partir dos dados obtidos em cada revista.

\section{RESULTADOS}

Foram verificados 931 artigos, dispostos nas quatro revistas de Geografia ao longo de 11 anos. No final deste artigo, foi anexado um APÊNDICE com a listagem contendo os títulos dos artigos identificados em cada ano e em cada revista. A seguir, os dados do levantamento realizado em cada revista.

\section{I - Revista Espaço Aberto (Figura 1)}

Foram 191 artigos publicados entre 2011 e 2020, mas apenas 7 (3,7 \%) abordaram o tema das 'UC' e nenhum deles tratou de 'uso público' 
Figura 1 - Revista Espaço Aberto - Publicações sobre 'UC' e total de artigos por ano. (2011-2020)

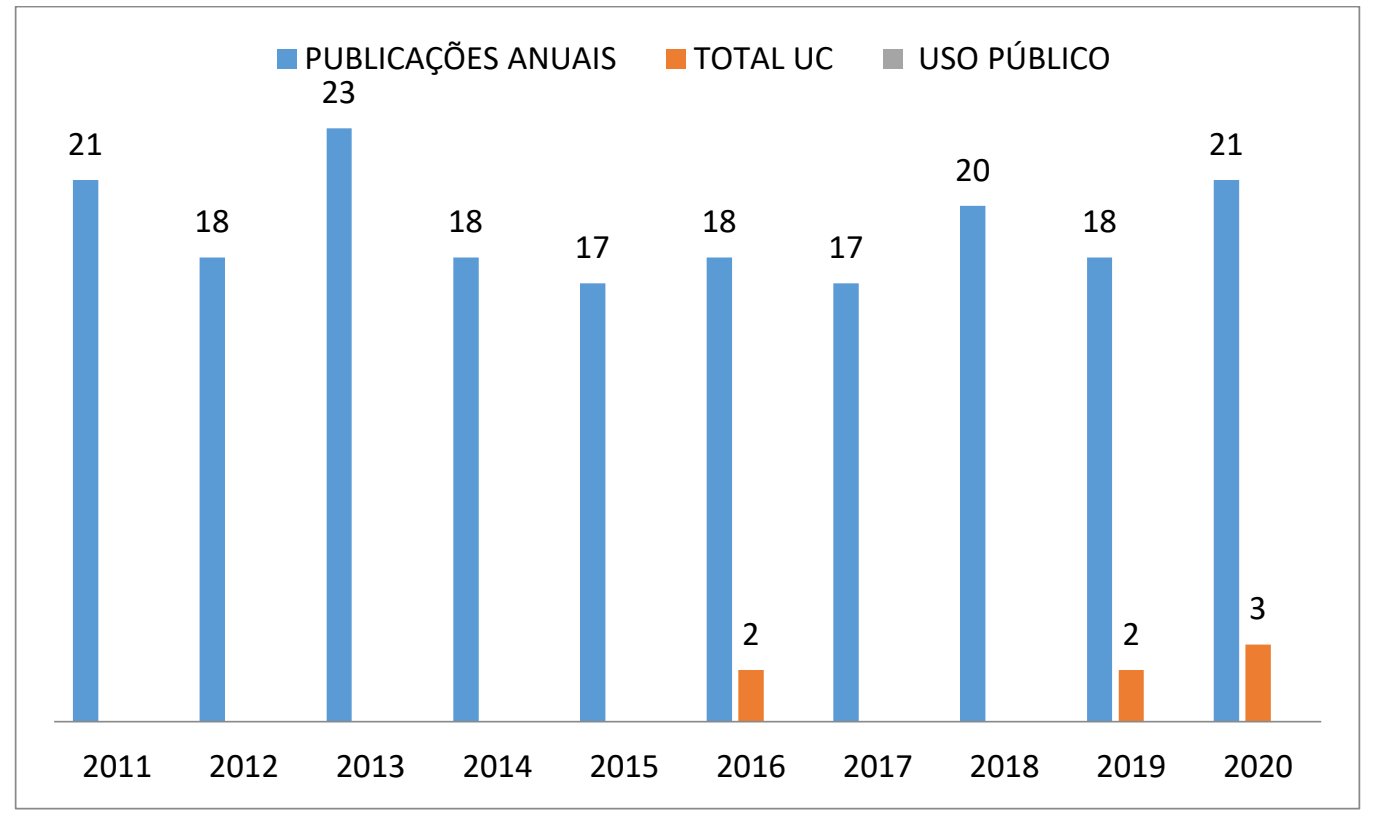

Fonte: Elaborado pelo autor.

A produção ao longo do período de avaliação se manteve entre 17 a 23 artigos. Somente em 2016, foram encontradas duas publicações que trataram especificamente sobre 'UC' e, em 2020, ocorreu o maior número de publicações sobre o tema (3).

\section{II - Revista GEOgraphia (Figura 2)}

Nos 203 artigos publicados pela revista GEOgraphia, 9 (4,4\%) tratavam do tema das 'UC', sendo quatro deles sobre 'uso público'.

Figura 2 - Revista GEOgraphia - Relação entre publicações anuais, em 'UC e 'uso público' (2010-2020)

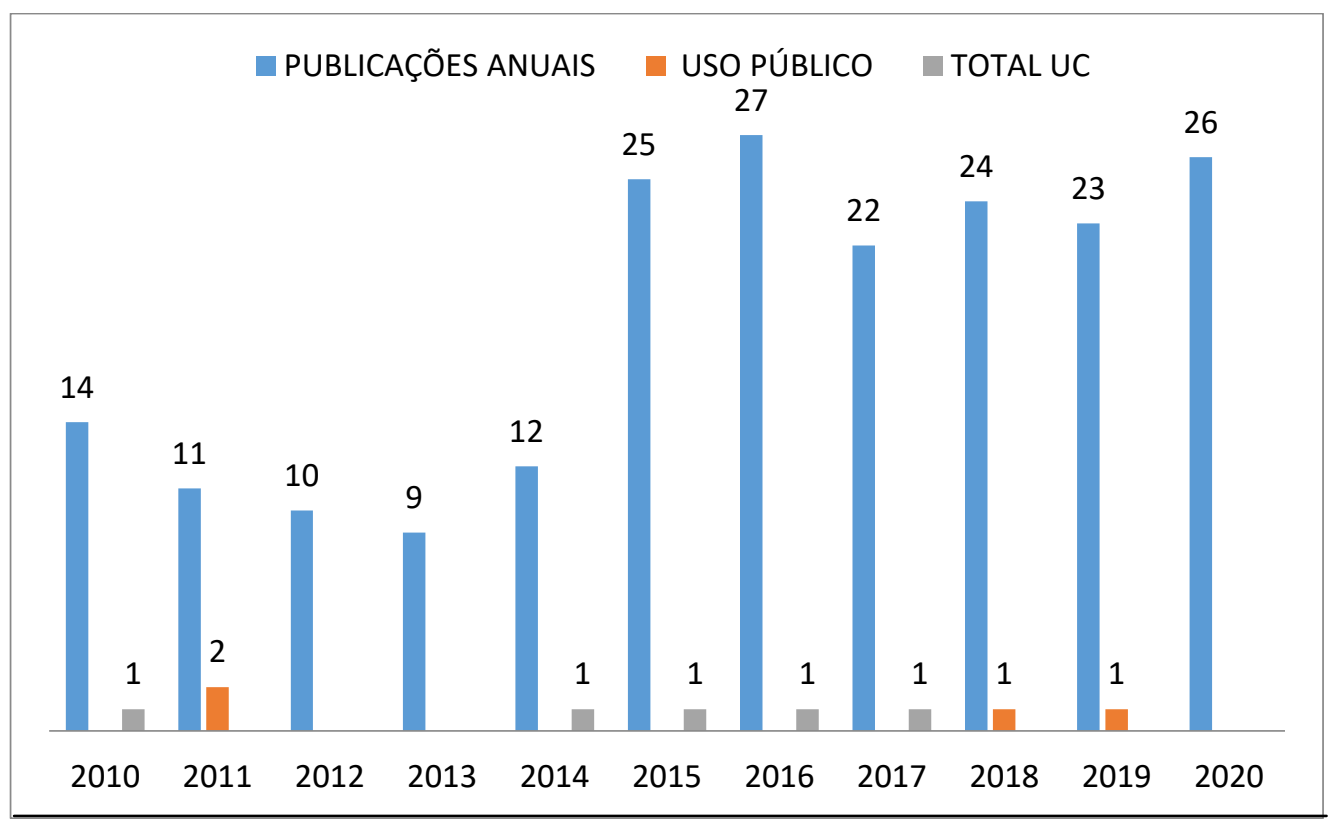

Fonte: Elaborado pelo autor

Pela Figura 2 constata-se maior regularidade nas publicações relativas às 'UC', pois durante os 11 anos avaliados, houve publicação em oito. De 2014 a 2019, observa-se uma publicação por ano sobre o assunto. 


\section{III - Revista GEO-UERJ (Figura 3)}

Nos 442 artigos publicados, 15 (3,4\%) abordaram o tema das 'UC', sendo que sete faziam referência direta ao 'uso público'. Comparativamente e em termos absolutos, esta revista foi a que mais publicou sobre o assunto.

Pela Figura 3 e semelhantemente à Revista GEOgraphia, houve regularidade, pois nos 11 anos de avaliação, ocorreram publicações sobre 'UC' em oito edições.

Figura 3 - Revista GEO-UERJ - Publicações sobre 'UC' e 'uso público' e total de artigos por ano. (2010 -2020).

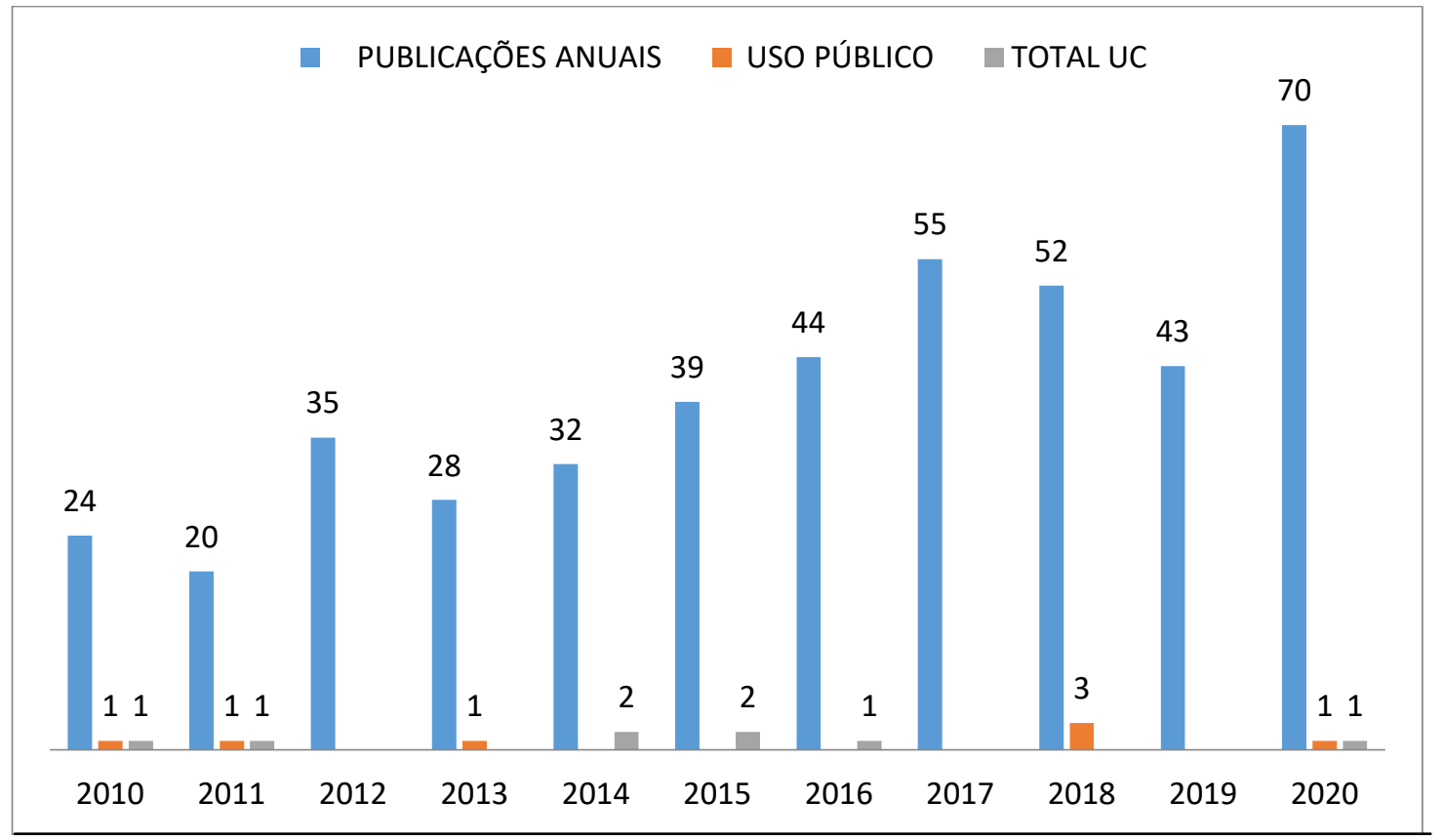

Fonte: Elaborado pelo autor

\section{IV - Revista CONTINENTES (Figura 4)}

A Revista CONTINENTES apresentou um total de 95 artigos publicados em nove anos de levantamento, sendo apenas $2(2,1 \%)$ abordando o tema das 'UC'. Nenhum destes trouxe resultados de pesquisas sobre 'uso público'.

Figura 4 - Revista CONTINENTES - Publicações sobre UC e total de artigos por ano. (2012 -2020).

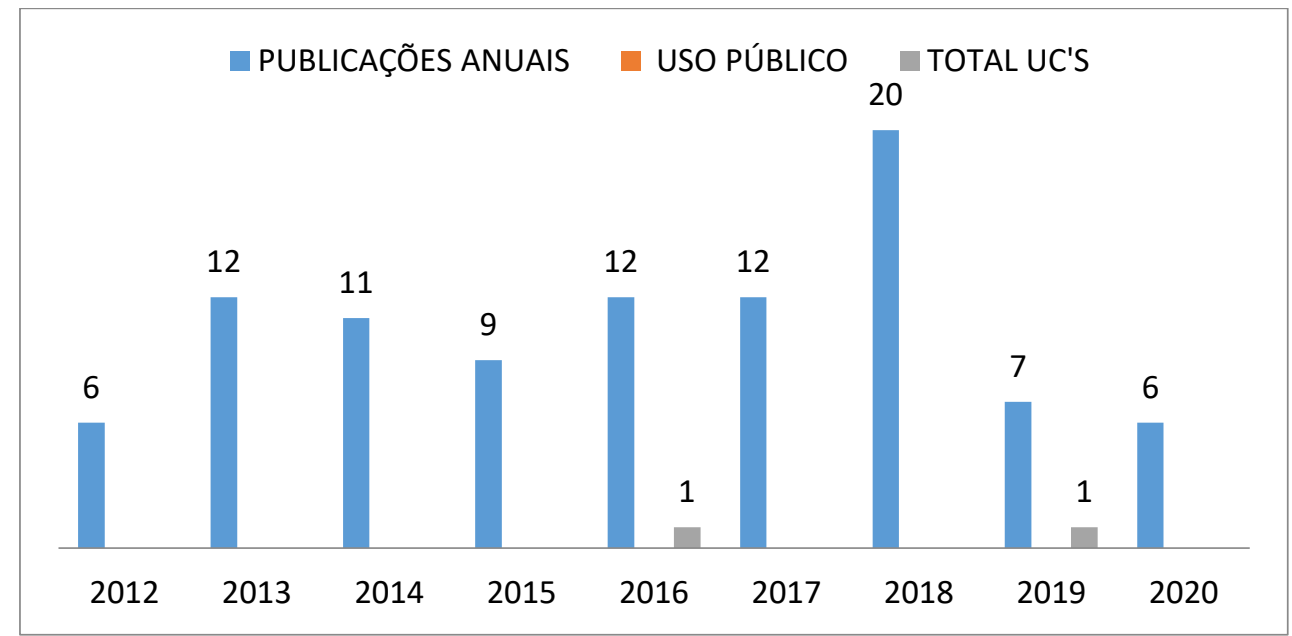

Fonte: Elaborado pelo autor.

Através da Figura 5 e do Quadro 3 é possível ter uma visão comparativa entre os resultados das publicações nas revistas selecionadas. 
Figura 5 - Comparação entre as revistas. Dados totais e específicos.



Fonte: Elaborado pelo autor

QUADRO 3 - Total de publicações por revista e artigos encontrados.

\begin{tabular}{|c|c|c|c|c|c|}
\hline REVISTAS & $\begin{array}{c}\text { ESPAÇO } \\
\text { ABERTO }\end{array}$ & GEOGRAPHIA & $\begin{array}{c}\text { GEO- } \\
\text { UERJ }\end{array}$ & CONTINENTES & TOTAIS \\
\hline $\begin{array}{c}\text { TOTAL DE } \\
\text { PUBLICAÇÕES }\end{array}$ & 191 & 203 & 442 & 95 & 931 \\
\hline ARTIGOS 'UC' & 7 & 5 & 8 & 2 & 22 \\
\hline 'USO PÚBLICO' & 0 & 4 & 7 & 0 & 11 \\
\hline $\begin{array}{c}\text { \% ARTIGOS } \\
\text { 'UC' }\end{array}$ & 3,7 & 4,4 & 3,4 & 2,1 & 3,6 \\
\hline
\end{tabular}

Fonte: Elaborado pelo autor.

Os dados indicam algumas diferenças entre as revistas, destacando-se o fato de que as edições da Geographia/UFF e da Geo-UERJ tiveram maior procura para publicações sobre 'UC' e também sobre 'uso público'. Destaca-se que ambas apresentam melhor qualificação junto ao sistema Qualis CAPES para publicações, respectivamente A2 e B1 (Quadro 2).

Percentualmente, considerando o total de publicações sobre o tema das UC ('UC' + 'uso público'), estas duas revistas também tiveram maior procura (4,4 e 3,4\%, respectivamente), apesar de que a revista Espaço Aberto/UFRJ teve um percentual ligeiramente maior que a revista Geo-UERJ $(3,7 \%)$, mas não teve publicações sobre 'uso público'.

A Revista Geo-UERJ teve o maior número de publicações sobre o tema 'uso público'(7), quase o dobro observado nas edições pesquisadas de Geographia (4).

\section{CONSIDERAÇÕES FINAIS}

Os resultados obtidos neste trabalho indicam baixa quantidade de publicações referentes ao tema das 'UC' e 'uso público' ao longo dos últimos 11 anos de avaliação. Dos 932 artigos publicados nas quatro revistas, detectamos apenas 33 artigos (3,6\%). Somente duas revistas (Geographia/UFF e Geo-UERJ) publicaram artigos falando sobre 'uso 
público' $(11$ artigos $=1,2 \%)$. A grande maioria de trabalhos publicados teve como objeto e/ou área de estudo, diversas UC espalhadas pelo país. As Revistas GEO-UERJ, Geographia e Espaço Aberto apresentaram um número total considerável de publicações científicas, porém com resultados pouco expressivos em relação aos temas estudados neste artigo.

Em princípio, pode-se supor que o pequeno número de publicações sobre 'uso público' é diretamente proporcional aos interesses e esforços existentes nesse campo de pesquisa. Provavelmente, ainda existem poucos pesquisadores da Geografia diretamente envolvidos nesse campo de trabalho, o que se reflete no baixo número de publicações, pelo menos nas revistas consideradas no presente levantamento.

Os estudos sobre as áreas protegidas na Geografia têm maior tradição, porém, no caso do 'uso público', ainda é considerado um tema novo e de baixo índice de publicação. O interesse social sobre as áreas legalmente protegidas tem aumentado ao longo das últimas décadas refletindo sobre o aumento da visitação. Os dados do ICMBio (Instituto Chico Mendes de Conservação da Biodiversidade) mostram que os Parques Nacionais da Tijuca e do Iguaçú, por exemplo, vêm recebendo a cada ano um contingente maior de visitantes ao longo da última década ${ }^{3}$. O incremento do turismo nacional e internacional, além de outros fatores, é responsável por esse aumento na visitação. O uso público, neste caso, torna-se um tema essencial para o planejamento e gestão adequada desses territórios, porém o ritmo dos estudos publicados nas revistas selecionadas para o presente levantamento, não expressou essa importância.

Como o uso público é um tema interdisciplinar existe a necessidade de formação de equipes multidisciplinares incluindo a participação de biólogos, turismólogos, sociólogos e geógrafos. No caso específico da Geografia, outros temas costumam atrair mais a atenção desses profissionais, havendo certa expectativa que os estudos sobre 'UC e uso público' aumentem gradativamente.

O baixo número de publicações específicas sobre o assunto nos periódicos da Geografia avaliados nos remete para busca de publicações em outras canais editoriais mais especializados. Por exemplo, a Universidade Federal Fluminense (UFF) através de seu programa de pós graduação em Geografia (Instituto de Geociências), mantém uma revista sobre Uso Público em Unidades de Conservação desde 2013, com periodicidade anual (https://periodicos.uff.br/uso_publico). Até 2019, foram publicados 83 artigos, o que demonstra a existência de um espaço editorial onde as pesquisas do tema podem e têm sido divulgadas. Será conveniente avaliar o perfil dessa produção e dos pesquisadores envolvidos nas pesquisas.

O potencial das publicações relativas ao 'uso público' é fator de grande importância para a valorização e melhoria das UC, principalmente no que concerne ao planejamento e o processo de visitação como retorno para todos aqueles que procuram essas áreas para sua recreação.

Portanto, há de ser considerar que esse trabalho é apenas uma base de levantamento para subsidiar as reflexões sobre a produção acadêmica em Geografia, estimulando outros pesquisadores em pesquisas demonstrem que o tema 'uso público' pode e deve ser estudado pelos geógrafos e não apenas divulgado nas revistas especializadas sobre o tema.

\footnotetext{
${ }^{3}$ https://www.icmbio.gov.br/portal/ultimas-noticias/20-geral/10216-visitacao-em-parques-nacionais-batenovo-recorde-em- 


\section{REFERÊNCIAS BIBLIOGRÁFICAS}

BRASIL. Sistema Nacional de Unidades de Conservação da Natureza. Lei 9.985 de 18 de junho de 2000 e decreto 4.340 de 22 de agosto de 2002. Ministério do Meio Ambiente, $2^{\mathrm{a}}$ ed. Brasília. 2002

BENSUSAN, N. Conservação da Biodiversidade em áreas protegidas. Rio de Janeiro: Editora FGV. 2006. 176p.

BOTELHO, A. L. M; VALLEJO, L. R. Uso de áreas de proteção ambiental: O caso do Manguezal da APA de Guapimirim. GEOGRAPHIA. Vol. 8, n.16, 2006.

DIEGUES, A. C. S. O mito moderno da natureza intocada. $1^{\circ}$ ed. Editora Hucitec. São Paulo, 1996, p. 169

GONÇALVES. C. W. P. Os (Des)Caminhos do meio Ambiente. 14 ed. Editora Contexto. São Paulo, 2008.

HENDEE, J. C.; STANKEY, G. H; LUCAS, R. C. Wilderness Management. 2. ed. Golden: North American Press, 1990. 537 p.

MILLER, K. R. Evolução do conceito de áreas de proteção oportunidades para o século XXI. In: Anais do I Congresso Brasileiro de Unidades de Conservação. Curitiba: IAP: UNILIVRE: Rede Nacional Pró Unidades de Conservação, Vol. 1: 3-21. 1997

MINISTÉRIO DO MEIO AMBIENTE. Diagnóstico da visitação em parques nacionais e estaduais. Brasília: Ministério do Meio Ambiente. Secretaria de Biodiversidade e Florestas, 2005.

RAMOS, P. M. Métodos Quantitativos e Pesquisa Em Ciências Sociais: Lógica e utilidade do uso da quantificação nas explicações dos fenômenos sociais. MEDIAÇÕ̃ES, Londrina, V.18, n.1, P. 55-65JAN/JUN.2013

RYLANDS, A. B., BRANDRON, K. Unidades de conservação brasileiras. Revista Megadiversidade, v. 1, n. 1, 2005.

VALLEJO, L. R. Uso público em áreas protegidas: atores, impactos, diretrizes de planejamento e gestão. In: Anais Uso Público em Unidades de Conservação. Niterói. RJ. vol. 1, p. 13-26, 2013.

. Os parques e reservas como instrumentos de ordenamento territorial. In: Ordenamento Territorial. ALMEIDA, Flávio, 2008 (ORG).

Unidade de conservação: uma discussão teórica à luz dos conceitos de território e de políticas públicas. GEOGRAPHIA, vol. 4, n. 8. 2002

Aspectos das políticas de governo e a questão da gestão territorial nas unidades de conservação do estado do Rio de Janeiro. GEOGRAPHIA, vol.7, n.13. 2005. 


\begin{tabular}{|c|c|}
\hline ANO & REVISTA ESPAÇO ABERTO - UFRJ (UC) \\
\hline \multirow[t]{2}{*}{2016} & $\begin{array}{l}\text { Interpretação Ambiental e Geodiversidade: Proposta de um Painel } \\
\text { Interpretativo sobre o Geossítio Pedra Furada, Parque Nacional de } \\
\text { Jericoacoara, Ceará }\end{array}$ \\
\hline & $\begin{array}{l}\text { Análise Geoambiental do Parque Natural Municipal Lagoa do Frio-Canindé } \\
\text { de São Francisco - Sergipe }\end{array}$ \\
\hline \multirow{3}{*}{2019} & $\begin{array}{l}\text { Interações entre Geografia e Educação Ambiental. O Caso da Implantação da } \\
\text { Reserva de Desenvolvimento Sustentável Mamirauá. }\end{array}$ \\
\hline & $\begin{array}{l}\text { Análise Espaço-Temporal do Uso da Superfície no Parque Nacional da Serra } \\
\text { da Capivara/PI a Partir do Sensoriamento Remoto }\end{array}$ \\
\hline & $\begin{array}{l}\text { A Concepção de Proteção da Natureza e as Estratégias da Conservação } \\
\text { Ambiental no Brasil: um Estudo de Caso Sobre o Parque Estadual da Ilha } \\
\text { Grande }\end{array}$ \\
\hline \multirow[t]{2}{*}{2020} & $\begin{array}{l}\text { Comportamento do NDVI em Savanas Considerando os Aspectos do } \\
\text { Ambiente - APA do Rio Pandeiros - MG }\end{array}$ \\
\hline & $\begin{array}{l}\text { Ribeirinhos em Resistência à Gestão Biocêntrica de Unidades de } \\
\text { Conservação Pública e Privada no Pantanal. }\end{array}$ \\
\hline
\end{tabular}

\begin{tabular}{|c|l|}
\hline ANO & \multicolumn{1}{c|}{ REVISTA GEOgrafia - UFF (Uso Público) } \\
\hline \multirow{2}{*}{2011} & $\begin{array}{l}\text { Território, Territorialidade e identidade dos Pescadores Artesanais: Subsídios } \\
\text { de Planejamento e Gestão de Reservas Extrativistas Marinhas }\end{array}$ \\
\cline { 2 - 2 } & $\begin{array}{l}\text { Múltiplos Olhares, Muitas Imagens: O Manejo dos Parques com base na } \\
\text { Complexidade Social }\end{array}$ \\
\hline 2018 & Conceitos Geográficos na Gestão das Unidades de Conservação Brasileiras \\
\hline 2019 & Avaliação da efetividade de áreas protegidas: conceitos, métodos e desafios \\
\hline ANO & \multicolumn{1}{|c|}{ REVISTA GEOgrafia - UFF (UC) } \\
\hline 2010 & O Território Tutelado - O caso do Aventureiro em Ilha Grande \\
\hline 2014 & $\begin{array}{l}\text { Migração Lateral do Canal do Rio Paraguai entre a Cidade de Cárceres e a } \\
\text { Estação Ecológica Ilha de Taiamã - Mato Grosso }\end{array}$ \\
\hline 2015 & A Proteção do Ecossistema Manguezal pela Legislação Ambiental Brasileira \\
\hline 2016 & $\begin{array}{l}\text { O Princípio da Subsidiaridade e sua relação com a APA do Município de } \\
\text { Ilha Comprida, SP }\end{array}$ \\
\hline
\end{tabular}

\begin{tabular}{|c|l|}
\hline ANO & \multicolumn{1}{|c|}{ REVISTA GEO UERJ - UFF (Uso Público) } \\
\hline 2010 & $\begin{array}{l}\text { Trilhas Interpretativas como Instrumento de Geoturismo e Geoconservação: } \\
\text { Caso da Trilha de Salto São Jorge, Campos Gerais do Paraná }\end{array}$ \\
\hline 2011 & Análise e diagnóstico de Parques Urbanos em Maringá. \\
\hline 2013 & $\begin{array}{l}\text { A eficácia do Planejamento Turístico Sustentável em Unidades de } \\
\text { Conservação da Natureza: o caso do Delta do Rio Jacuí, RS }\end{array}$ \\
\hline \multirow{2}{*}{2018} & $\begin{array}{l}\text { O Desafio da Educação Ambiental em Área Protegida na Cidade do Rio de } \\
\text { Janeiro }\end{array}$ \\
\cline { 2 - 2 } & $\begin{array}{l}\text { Práticas Ambientais no Parque Ecológico Bosque dos Papagaios, BOA } \\
\text { VISTA / RR }\end{array}$ \\
\cline { 2 - 2 } & $\begin{array}{l}\text { Conservação da Natureza e Gestão Integrada no Mosaico Sertão Veredas } \\
\text { Peruaçu - Norte de Minas Gerais }\end{array}$ \\
\hline 2020 & $\begin{array}{l}\text { Geoturismo e Roteiros Turísticos: Propostas para o Parque Nacional de } \\
\text { Ubajara, Ceará }\end{array}$ \\
\hline
\end{tabular}

\begin{tabular}{|l|l|}
\hline ANO & \multicolumn{1}{|c|}{ REVISTA GEO UERJ (UC) } \\
\hline 2010 & $\begin{array}{l}\text { Avaliação da Efetividade da Gestão Participativa na APA da Serra da } \\
\text { Mantiqueira }\end{array}$ \\
\hline \multirow{2}{*}{2011} & $\begin{array}{l}\text { Aplicação da Abordagem Morfoestatigráfica para a Interpretação de "Areias } \\
\text { Brancas" em um Setor Colinoso no Litoral Sul do Estado de Pernambuco: O } \\
\text { Caso da Reserva Ecológica do Camaçari, Município de Cabo de Santo } \\
\text { Agostinho }\end{array}$ \\
\hline & Delimitação Espacial de uma Unidade de Conservação: O Caso da Área de \\
\hline
\end{tabular}


2014 Proteção Ambiental de Vacaraí-Mirim / RS

A Caracterização Ambiental da Ampla Área de Estudo do Morro Gaúcho, em Arroio do Meio e Capitão / RS, Visando à Criação de uma Unidade de Conservação

2015 Observações em Superfície Modelada na APA Petrópolis, Rio de Janeiro

Análise Socioambiental a partir dos Zoneamentos Ecológico Econômico da Área de Proteção Ambiental das Lagoas e Dunas do Abaeté

2016 Avaliação de Áreas de Preservação Permanente em Superfície Planimétrica e Superfície Modelada na Área de Proteção Ambiental da Região Serrana de Petrópolis-RJ

2020 A Espacialidade Rural das Reservas Particulares do Patrimônio Natural (RPPN) no Estado do Rio de Janeiro

\begin{tabular}{|c|l|}
\hline ANO & \multicolumn{1}{|c|}{ REVISTA CONTINENTES - UFRRJ (UC) } \\
\hline 2016 & $\begin{array}{l}\text { Uso de Mineração de Dados para Mapeamento da Cobertura da Terra em } \\
\text { Imagem OLI/ Landsat 8 no Parque Nacional do Itatiaia }\end{array}$ \\
\hline 2019 & $\begin{array}{l}\text { Espacialização Fitofisionômica de Espécies Arbóreas da Floresta Nacional } \\
\text { Mário Xavier, Seropédica - RJ }\end{array}$ \\
\hline
\end{tabular}

